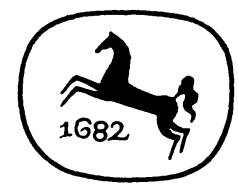

SAMMLUNG METZLER

REALIENBÜCHER FÜR GERMANISTEN

ABT. G: DOKUMENTATIONEN

(REIHE b: ZU UNRECHT VERGESSENE TEXTE) 


\title{
DIE NEUE CECILIA
}

FAKSIMILEDRUCK

DER ORIGINALAUSGABE VON I794

\author{
$\longrightarrow$ \\ MIT EINEM NACHWORT \\ VON \\ HANS JOACHIM SCHRIMPF
}

MCMLXII

J.B. METZLERSCHE VERLAGSBUCHHANDLUNG STUTTGART 
Die Hamburger Staats- und Universitätsbibliothek stellte ihr Exemplar der Originalausgabe von 1794 dankenswerterweise für die Reproduktion zur Verfügung.

ISBN 978-3-476-98829-4

ISBN 978-3-476-98828-7 (eBook)

DOI 10.1007/978-3-476-98828-7

(C)

Springer-Verlag GmbH Deutschland 1962

Ursprünglich erschienen bei J. B. Metzlersche Verlagsbuchhandlung

und Carl Ernst Poeschel Verlag GmbH in Stuttgart 1962 